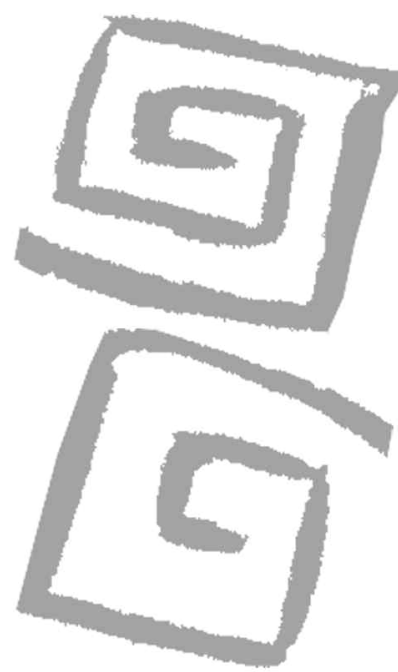

\title{
Derecho a la salud: un modelo para la determinación de los contenidos mínimos y periféricos
}

\author{
The right to health: a model for \\ determining the contents of the minimum core \\ and the periphery
}

Ronconi, Liliana M. ${ }^{1}$

\footnotetext{
${ }^{1}$ Abogada. Becaria doctoral, Universidad de Buenos Aires. Investigadora adscripta, Instituto de Investigaciones Jurídicas y Sociales "L. A. Gioja", Facultad de Derecho, Universidad de Buenos Aires, Argentina.

Imronconi@googlemail.com
}

RESUMEN El derecho a la salud ha sido fuertemente reconocido por los tribunales argentinos, pero lo cierto es que solo goza de dicho derecho quien tiene posibilidad de acceder a la justicia. Por lo tanto, los grupos tradicionalmente excluidos, que por diferentes motivos no pueden hacer oír sus reclamos en sede judicial, no se benefician con el reconocimiento logrado hasta ahora en las diferentes resoluciones judiciales. Teniendo en cuenta estas prácticas desigualitarias institucionalizadas se plantea aquí un modelo que implica entender el derecho a la salud como verdadero derecho. Para esto se realiza una distinción entre el derecho a la salud como regla (en lo que se refiere al contenido mínimo o esencial de dicho derecho) y el derecho a la salud como principio (respecto del contenido periférico), demostrándose así cómo el derecho a la salud considerado como regla y como principio podría llegar a otorgar mayor igualdad en el reconocimiento de este derecho respecto de los grupos desaventajados, que carecen de acceso a la justicia.

PALABRAS CLAVE Derecho a la Salud; Justicia Social; Justicia Redistributiva; Grupo Social.

ABSTRACT The right to health has been widely recognized in the Argentine courts, however only those who have the ability to access the justice system are able to fully enjoy that right. Therefore traditionally excluded groups, who for different reasons have not been able to make their demands heard in a judicial court, do not benefit from the recognition gained up to this point in the different judicial resolutions. Taking into account these institutionalized unequal practices, this article suggests a model for understanding the right to health truly as a right. A distinction is made between the right to health as a rule (understood as the minimum or essential core of that right) and the right to health as a principle (understood as the periphery of the right). In this way, it is shown how considering the right to health as both a rule and as a principle could offer greater equality in recognition of that right for disadvantaged groups that lack access to the justice system.

KEY WORDS Right to Health; Social Justice; Redistributive Justice; Social Group. 


\section{INTRODUCCIÓN}

La Organización Mundial de la Salud (OMS) sostiene que la salud es el estado de completo bienestar físico, mental y social, constituyendo un derecho esencial de toda persona (1). Ahora bien, conforme a lo dispuesto tanto en la Constitución Nacional argentina como en diferentes tratados internacionales de derechos humanos, el derecho a la salud no puede ser interpretado en forma aislada pues convive con otros derechos y, en especial, con el mandato de igualdad. Por esto, se sugiere aquí trabajar la tesis que sostiene que el derecho a la salud debe poder ser disfrutado en condiciones de igualdad estructural de oportunidades (2-11).

Pero ¿cómo garantizar la igualdad estructural de oportunidades para el ejercicio real del derecho a la salud en contextos de exclusión social? Esta pregunta nos lleva a los problemas de especificación del contenido de los derechos sociales en general y, particularmente, del derecho a la salud. En este sentido, es posible sostener que una de las formas de garantizar esa igualdad es a través del establecimiento de métodos claros para la determinación de "contenidos mínimos" y de otros contenidos más allá de este umbral que podríamos Ilamar "contenidos periféricos". En este sentido, es un hecho aceptado que los derechos sociales generan para el Estado obligaciones de hacer, pero uno de los argumentos que se utilizan para negar la plena vigencia a estos derechos gira en torno a la dificultad para determinar el alcance de estas obligaciones de hacer positivo $(12,13)$. Existe mucha bibliografía que intenta refutar esta dificultad pero podemos pensar que aún resta desarrollar una dogmática más acabada de los derechos sociales (14).

La propuesta de este trabajo es contribuir en alguna medida a ese propósito, evaluando el carácter de reglas o principios de las obligaciones estatales de prestación que surgen de los derechos sociales. Para ello, nos concentraremos en la distinción entre reglas y principios en la versión desarrollada en la Teoría de los Derechos Fundamentales (12). Haré especial referencia al derecho a la salud, como parte de los derechos sociales que han sido reconocidos en la Constitución Nacional argentina, entre otros.
El trabajo se divide en tres secciones: en la primera, se realizará una breve mención de los problemas que traen aparejados los derechos sociales, haciendo especial hincapié en el problema de (des)igualdad que representa el desarrollo de derechos sociales por vía judicial; en la segunda, se estudiarán las implicancias del modelo de las reglas y de los principios, trabajando con el principio de proporcionalidad o ponderación y, especialmente, con el "modelo de ponderación orientado por reglas" (ein regelorientiertes Abwägungsmodell) desarrollado por Clérico para diferenciarlo de la mera ponderación o del balancing ad hoc $(15,16)$. De esta manera, se pretende determinar cuál de estos modelos debe regir al momento de solucionar casos de derechos sociales (específicamente de derecho a la salud) o si configuran un solo modelo, donde la aplicación del derecho a la salud como regla o como principio depende del caso en cuestión; en la tercera sección se presentarán algunas conclusiones acerca de la necesidad de lograr un reconocimiento igualitario del derecho a la salud y de cómo el modelo propuesto puede ser un motor de cambio en este sentido.

\section{DERECHOS SOCIALES: LOS "PROBLEMAS" QUE ENCIERRAN}

\section{¿Meros mandatos o verdaderos derechos?}

Mucho se ha escrito en la doctrina respecto del alcance de los derechos sociales, y se trata de una discusión que aún no está zanjada. Vale aclarar que en este trabajo solo se tomarán en cuenta algunas de las críticas que se realizan al concepto de "derechos sociales" (17-20). En este sentido, un sector de la doctrina entiende que los derechos sociales son de desarrollo progresivo, es decir, meros mandatos dirigidos al legislador para ser desarrollados paulatinamente. Así, el progreso de los derechos sociales sería una cuestión de creación y estructuración de políticas públicas que quedaría por completo en manos del legislador. Desde esta perspectiva, los derechos sociales serían derechos incompletos, por lo tanto no podrían ser invocados frente a la justicia. 
Como característica de este carácter programático se resaltan dos aspectos: la generalidad y su dependencia de recursos presupuestarios. Por un lado, se argumenta que la generalidad de los enunciados que instituyen derechos sociales requiere de una reglamentación para poder determinar la medida de las prestaciones debidas, esto es, cuál es el objeto de ese derecho. Este rasgo afecta el reclamo en sede judicial, al desconocerse su contenido.

Por otro lado, también se señala la vinculación de los derechos sociales con los recursos presupuestarios, recursos que son manejados exclusivamente por los poderes políticos, pero no por el Poder Judicial. Se ha dicho que:

...cuando la reparación de una violación de derechos económicos, sociales y culturales importa una acción positiva del Estado que pone en juego los recursos presupuestarios, o afecta de alguna manera el diseño o la ejecución de políticas públicas, o importa tomar una decisión acerca de qué grupos o sectores sociales serán prioritariamente auxiliados o tutelados por el Estado, los jueces suelen considerar tales cuestiones como propias de la competencia de los órganos políticos del sistema. (13 p.127)

De esta manera, muchos jueces argumentan respecto de la imposibilidad de fijar ellos mismos políticas que implicarían el uso de los recursos presupuestarios.

Ahora bien, sabemos que rigen en el ámbito de los derechos sociales los principios de realización progresiva y de no regresividad. El principio de no regresividad obliga a los Estados, una vez reconocido determinado alcance o contenido de un derecho, a no volver atrás negando ese alcance.

Si deliberadamente adopta alguna medida regresiva, el Estado Parte tiene la obligación de demostrar que fue implantada tras la consideración cuidadosa de todas las alternativas y que se justifica plenamente en relación con la totalidad de los derechos previstos en el Pacto y en el contexto del aprovechamiento pleno del máximo de los recursos de que se disponga el Estado Parte. (21)
Asimismo, el principio de progresividad

...consiste en la adopción de providencias, especialmente económicas y técnicas -en la medida de los recursos disponibles, sea por vía legislativa u otros medios apropiados- para lograr progresivamente la plena efectividad de ciertos derechos económicos, sociales y culturales. (22 p.34)

Entonces ambos principios implican, por un lado, la obligación del Estado de adoptar políticas que mejoren la situación de los derechos logrando un avance en su delimitación y, por otro, evitar aquellas decisiones que impliquen una disminución en su grado de concreción (23).

Esto significa que los Estados tienen la obligación concreta y constante de avanzar lo más expedita y eficazmente posible hacia la plena realización, en nuestro caso, del artículo 12 del Pacto Internacional de Derechos Económicos, Sociales y Culturales (PIDESC) (24).

Sin embargo, los Estados no pueden darse por satisfechos con el reconocimiento de un mínimo del derecho, porque el cumplimiento de los derechos prestacionales es progresivo, lo que significa que este cumplimiento debe ir en aumento y no puede quedarse estático con respecto a determinadas prestaciones. Así, los principios de realización progresiva y de no regresividad son conceptos destinados a hacer cada vez más rigurosos los estándares de exigibilidad, porque exigen que sea el Estado quien deba justificar que ha hecho todo lo posible (respecto de los recursos) para satisfacer el derecho. De esta manera, toda medida regresiva deberá estar justificada por razones de suficiente peso (22).

Estos principios -progresividad y no regresividad- han sido utilizados por la doctrina y aplicados por la jurisprudencia para reafirmar el carácter de derecho de los derechos económicos, sociales y culturales (DESC) (25); por lo que la postura que sostiene que los derechos sociales son meros mandatos dirigidos al legislador ha ido cambiando, considerándose que los DESC son verdaderos derechos, que deben realizarse en la mayor medida posible y que deben poder ser invocados ante los tribunales de justicia, y los particulares deben poseer a su alcance adecuadas herramientas para su protección. Así, si bien los Estados cuentan con un grado de 
discreción a la hora de seleccionar las herramientas para cumplir con estos derechos, esto no implica que no exista una obligación de actuar progresivamente. Por esto, es posible sostener que el Estado no solo tiene la obligación de no interferir en el ejercicio de los derechos individuales sino que también tiene el deber de realizar acciones positivas para que el ejercicio de ciertos derechos no se torne ilusorio, posición sostenida en la decisión "Asociación Benghalensis", por la Corte Suprema de Justicia de la Nación (26). En este sentido, la Resolución 32/130 de la Asamblea General de las Naciones Unidas establece que:

1.a) Todos los derechos humanos y libertades fundamentales son indivisibles e interdependientes; deberá prestarse la misma atención y urgente consideración a la aplicación, la promoción y la protección tanto de los derechos civiles y políticos como a los derechos económicos, sociales y culturales; b) La plena realización de los derechos civiles y políticos sin el goce de los derechos económicos, sociales y culturales resulta imposible... (27 p.160-161)

Podemos concluir entonces, que el carácter de verdadero derecho del derecho a la salud ha sido ampliado tanto por la doctrina como por las decisiones de los tribunales, estableciéndose la obligación del Estado de cumplir con el mismo. Sin duda todos estos avances resultan de gran importancia, pero también traen aparejados otros problemas. Esto nos Ileva al siguiente punto.

\section{La afectación de la igualdad a la hora de resolver casos de derecho a la salud}

Ciertamente los tribunales han avanzado en el reconocimiento de los derechos sociales, brindando de a poco argumentos para sostener la postura respecto de su exigibilidad (a), y esto ha sido especialmente relevante en el ámbito del derecho a la salud (b). En los últimos años ha existido allí un aumento del litigio individual y colectivo, con el objeto de obtener el cumplimiento efectivo del derecho a la salud frente a la falta de cumplimiento por parte del Estado nacional o local (c) e incluso por los particulares, y existe un importante activismo judicial a fin de lograr mayores garantías en tales derechos (34). Por ejemplo, el caso "Comunidad Toba del Chaco", causa presentada por el Defensor del Pueblo (amparo colectivo) contra la Provincia del Chaco y el Estado nacional cuando ya habían muerto 19 personas por desnutrición, a fin de que se los condene a que adopten las medidas necesarias para modificar las actuales condiciones de vida de las poblaciones indígenas las que, debido a las reiteradas y sistemáticas omisiones en que han incurrido los demandados en prestar la debida asistencia humanitaria y social, se encuentran en una situación de exterminio silencioso, progresivo, sistemático e inexorable. Asimismo, solicita que se los condene a que garanticen a dichas comunidades una real y efectiva calidad de vida digna que les permita el ejercicio de los derechos a la vida, a la salud, a la asistencia médico-social, a la alimentación, al agua potable, a la educación, a la vivienda, al bienestar general, al trabajo, a la inclusión social, entre otros, y que tales derechos sean satisfechos de manera continua y permanente. Otros ejemplos son los casos "Asociación Benghalensis y otros c/ Ministerio de Salud y Acción Social, Estado Nacional s/ amparo ley 16.986" del 1 de junio de 2000; y el caso "Ministerio de Salud y/o Gobernación s/ acción de amparo", del 31 de octubre de 2006.

Sin embargo, es necesario manejarnos con cautela en este punto: en materia de derechos sociales una resolución podría beneficiar a una persona o un sector pero no a todos, y esto puede ser considerado como un trato desigualitario. Así, resulta esencial tener en cuenta la desigualdad que este sistema impone porque existen casos donde determinados grupos (en especial, grupos vulnerables) no ven satisfecho su derecho, pero tampoco reclaman ante los órganos del Estado. Por otra parte "el hecho de que la Corte asuma el papel de protector del derecho en determinados casos particulares no soluciona aún el problema mayor derivado de la inacción u omisión de las actividades que a los otros dos órganos les competen asumir" (35). En otras palabras, existe una gran cantidad de conflictos que por diferentes causas (desconocimiento del derecho, dificultades económicas y/o de tiempo, desconfianza en el gobierno o en el sistema judicial, 
sujeción de los ingresos familiares a la ayuda social discrecional) no se traducen en reclamos administrativos o litigios (36,37 p.315). Esta situación se complejiza cuando los afectados son grupos que sufren una desigualdad estructural (grupos económicamente desaventajados, mujeres, pueblos originarios, etc.), como por ejemplo en el caso "Ramos" (38). En este caso existió un reclamo planteado por una mujer, madre soltera de ocho hijos que vivía "en un grado extremo de pobreza" pues habitaba en una humilde vivienda -prestada gratuitamente- junto con los niños cuyas edades oscilaban entre los nueve meses y quince años y no tenía trabajo. Una de sus hijas -Mariana S. Ramos- debía ser intervenida quirúrgicamente por padecer de cardiopatía congénita. La niña sufría desnutrición y no pudo ser operada ya que, al momento de tener turno en el Hospital Garrahan, su mamá no pudo trasladarla por carecer de medios económicos y lugar donde dejar a sus otros hijos. Asimismo, la actora sostenía que a su paupérrima condición económica se le sumaban sus carencias educativas, de manera que ella y sus hijos se encuentran inmersos en una pobreza estructural de la cual no pueden salir sin ayuda estatal. Sus hijos ni siquiera podrán completar sus estudios y sufren de desnutrición -y en algunos casos falta de maduraciónpor carencia de alimentación en cantidad y calidad adecuadas. De este modo, reclamaba tanto al Estado nacional como al provincial: a) que respeten los derechos que les asisten (a ella y a sus hijos) a una alimentación sana, a la salud, a la educación y a una vivienda digna, y que, como consecuencia de ello, les suministren "de manera concreta, efectiva, continua y mensual una cuota alimentaria" que les permita satisfacer sus necesidades básicas y vivir dignamente; b) que se otorgue a su hija Mariana S. Ramos las prestaciones médicas necesarias de acuerdo con su estado de salud y se remuevan para ello los condicionamientos que han impedido hasta ahora la plena y efectiva concesión de su derecho; c) que provean a sus seis hijos en edad escolar de las condiciones materiales (ropa, calzado, libros y útiles escolares y gastos de transporte) necesarias para concurrir a un establecimiento educacional; la Corte Suprema de Justicia de la Nación Argentina sostuvo que no corresponde condenar al Estado, mediante una sentencia judicial, a otorgar un subsidio y otros servicios sociales a la actora, cabeza de una familia numerosa e inmersa en una situación de pobreza extrema, cuando se prevé el acceso a un subsidio (madre soltera con más de 7 hijos) y el acceso a la educación y la salud está garantizado. Así, es posible afirmar que "los sectores sociales bajo condiciones estructurales de desigualdad y exclusión son las víctimas principales de este déficit institucional que afecta derechos políticos, sociales y civiles" (36 p.300, 39). Es por eso que aquí se sostiene que, si bien es positivo el avance que ha realizado la jurisprudencia respecto del reconocimiento de los derechos sociales (y en particular en el derecho a la salud), es necesario cuestionar la eficacia de este sistema.

El resultado de esto es que en Argentina solo goza del derecho a la salud quien tiene dinero para costear el tratamiento, quien pertenece a una obra social o medicina prepaga que funciona correctamente o quien ha logrado un reconocimiento administrativo o judicial de su derecho. Lamentablemente no todos tienen dinero suficiente para hacer frente a problemas de salud, no todos cuentan con una obra social, y son pocos los que logran acceder al servicio de justicia.

En Argentina, existen entre 5.000.000 y 3.000.000 de afiliados a empresas de medicina privada (prepagas) y alrededor de 15.000.000 de afiliados a obras sociales (40). Por lo tanto, podemos sostener que casi la mitad de la población (sobre un total de 40.000.000) carece de seguro médico, dependiendo de los hospitales públicos:

...la falta de integración entre los distintos subsectores -público, seguridad social, privadoes una de las particularidades del sistema [de salud], agravada, además, porque cada uno de ellos acusa un elevado grado de fragmentación. El sector público aporta a este cuadro general su división según jurisdicciones -nacional, provincial y municipal-, niveles entre los cuales no existe el grado necesario de coordinación. (41 p.62)

Así, solo garantiza y puede ver satisfecho su derecho a la salud quien consigue acceder a la justicia, lo que implica no solo conocimiento de la posibilidad de efectuar el reclamo sino también costos -dinero y tiempo- para poder 
afrontar la acción judicial. Si bien existen servicios de asesoramiento gratuito en muchas partes del país, estos generalmente se concentran en las grandes ciudades con lo cual las personas que habitan zonas carenciadas están lejos de acceder a los mismos. Existen además patrocinios jurídicos gratuitos de las universidades públicas desde principios del siglo XX (por ejemplo, el de la Universidad de Buenos Aires) y de ONG que atienden estas cuestiones, pero lamentablemente no alcanzan a satisfacer la gran cantidad de demandas sociales. Por ello, resulta necesario fijar un determinado contenido del derecho a la salud que sea indisponible para la judicatura pero, principalmente, para los demás actores esenciales en el proceso de reconocimiento del derecho a la salud (legisladores, poder ejecutivo nacional y provincial en su carácter de administrador del sistema público nacional y provincial respectivamente, obras sociales y empresas de medicina privada). En este sentido, en el punto 47 de la Observación General 14, se establece que "un Estado Parte no puede nunca ni en ninguna circunstancia justificar su incumplimiento de las obligaciones básicas enunciadas en el párrafo 43 supra, que son inderogables" (42). Esto nos Ileva al segundo punto, donde intentaremos establecer un "contenido esencial" del derecho a la salud al cual puedan acceder todos los ciudadanos.

\section{ENTRE REGLAS, PRINCIPIOS Y EL "MODELO DE PONDERACIÓN ORIENTADO POR REGLAS"}

Como se sostuvo al comienzo de este trabajo, los problemas que se presentan al momento de resolver casos vinculados con derechos sociales, especialmente respecto del derecho a la salud, son: 1) la determinación de cuándo el tratamiento o el medicamento es necesario (y por lo tanto debe ser cubierto por el sistema de salud) porque de lo contrario resultaría afectado el propio derecho invocado; 2) las cuestiones de igualdad estructural que trae aparejado el desarrollo de los derechos sociales por vía judicial, pues continúan resultando afectados los grupos desaventajados.
De esta manera, proponemos una distinción en lo que respecta al derecho a la salud: la interpretación del derecho a la salud como regla y como principio. Tenemos ciertos tratamientos que nadie dudaría de que resultan urgentes y necesarios y que no pueden ser negados a ninguna persona. Se trata de aquellos casos (d), donde lo que está en juego es la vida de la persona, en el sentido de que lo que está en riesgo es la existencia misma del enfermo. Estos casos se caracterizan porque "la obligación estatal de hacer positiva es impostergable, en caso contrario lo que se viola no es solo el derecho a la salud sino también el derecho a la subsistencia de la persona" (44). En este punto, es posible señalar que "la negación de un nivel mínimo de asistencia médica y de medicamentos puede ser contraria a la vida digna de un individuo [...] tal circunstancia es irreconocible con el derecho a la vida" (45 p.218). No puede existir duda respecto de la obligación de su cumplimiento. En estos casos, podríamos decir que el derecho a la salud actúa como regla, en el sentido establecido por Robert Alexy (12). La doctrina alemana ha discutido ampliamente las teorías que pretenden determinar el contenido de los derechos (teorías absolutas, relativas, espaciales, etc.) $(12,15,17,46,47)$; pero vale aclarar que el interés de este artículo no es elaborar una teoría filosófica respecto del contenido de los derechos sociales, sino más bien lograr su reconocimiento igualitario en la práctica social y jurídica.

Es bien conocido que una regla "es una restricción de un derecho fundamental cuando, con su vigencia [...] aparece una nolibertad definitiva o un no-derecho definitivo de igual contenido" (12 p.274). Las reglas presentan un carácter definitivo, pueden ser cumplidas o no; es decir, si se da el supuesto de hecho de la norma se sigue la solución: por ejemplo, si voy circulando en automóvil y veo un semáforo con luz roja entonces tengo la obligación de detenerme; esta obligación es definitiva. En estos casos se aplica el modelo de la subsunción y no corresponde una ponderación de derechos: "las normas sobre contenidos mínimos de los derechos sociales se aplican como reglas (modelo de la subsunción). El contenido mínimo del derecho no puede ser ponderado o graduado frente a otros principios" (44). 
Es por esto que se adopta una teoría del contenido esencial de los derechos (e). Esto implica adherir a lo que sostiene la Observación General 14 (42) sobre que existen ciertas obligaciones básicas que son inderogables. Estas obligaciones caen dentro del contenido esencial ( $f$ ) del derecho a la salud que es indisponible. Es decir, dada determinada característica o enfermedad (esto será ampliado posteriormente) el Estado debe afrontar el tratamiento, no pudiendo justificar en ningún caso su incumplimiento (alegando por ejemplo, que los recursos son destinados a afrontar otros servicios u otros problemas) pues, en estas circunstancias, el derecho a la salud presenta un núcleo esencial, un mínimo inquebrantable que no podrá ser dejado de lado en ninguna circunstancia, tanto por el Estado como por los particulares. Un ejemplo sencillo podría ser el derecho que tienen las personas portadoras de VIH. Estas personas tienen derecho a recibir un tratamiento (adecuado y bajo condiciones adecuadas) que debe ser costeado por el sistema de salud, sin que se pueda recurrir al argumento de la escasez de recursos o al argumento que sostiene que su cumplimiento pone en juego la financiación del sistema.

Ahora bien, hay que reconocer que hablar de un contenido mínimo digno de los derechos no significa negar la existencia de mayores alcances de estos, alcances que también son exigibles judicialmente (44 p.494, 49 p.57). En este sentido, existen otros casos donde la necesariedad del tratamiento es más dudosa pues, en principio, no estaría en juego la salud en el sentido que trabajamos anteriormente, es decir, en estos casos la afección no pondría en riesgo la vida (existencia) de la persona. Son casos que caen fuera de lo que hemos caracterizado como contenido esencial, pero en los cuales pueden, sin embargo, resultar afectados el derecho a la salud -tomando el concepto amplio de salud brindado por la OMS (1)-, a la dignidad, a la integridad. En definitiva, son casos en donde lo que resulta afectado es el derecho a vivir una vida digna, derecho que defiende, en último término, toda sociedad democrática.

Estos casos son caracterizados por la doctrina como "casos difíciles" (17). A modo de ejemplo, caen dentro de la categorización de casos difíciles las siguientes cuestiones: ¿debe afrontar el Estado los tratamientos de fertilización asistida o de implantes mamarios?; ¿deben cubrir las empresas de medicina privada los costos de las cirugías estéticas? $(50,51)$. Y es aquí donde se entiende que el derecho a la salud actúa como principio. Al respecto, la dogmática de los derechos fundamentales ha establecido que "Ios principios ordenan que algo debe ser realizado en la mayor medida posible, teniendo en cuenta las posibilidades jurídicas y fácticas" (52 p.20). Por lo tanto, no contienen mandatos definitivos (como las reglas) sino solo prima facie. Sostiene Alexy que "los principios carecen de contenido de determinación con respecto a los principios contrapuestos y las posibilidades fácticas" (12 p.99). Y entiende así que los principios son mandatos de optimización. De este modo, los casos de conflictos de esta "parte" del derecho con otros derechos fundamentales deberán resolverse mediante la ponderación (g), teniendo en cuenta el peso de los principios en pugna.

\section{La solución de la colisión consiste más bien en que, teniendo en cuenta las circunstancias del caso se establece entre los principios una rela- ción de precedencia condicionada. La determi- nación de la relación de precedencia condicio- nada consiste en que, tomando en cuenta el caso, se indican las condiciones bajo las cuales un principio precede al otro. Bajo otras condicio- nes, la cuestión de la precedencia puede ser solucionada inversamente. (12 p.92) (cursivas del original)}

Esto implica que un principio puede ser dejado de lado cuando se enfrenta a otro principio de mayor peso, porque

\footnotetext{
...a diferencia del contenido esencial, la periferia [ámbito donde el derecho a la salud actúa como principio] puede ser restringida, según las necesidades que se deriven de otros derechos, bienes o intereses que aparezcan tipificados en la Constitución o que sean relevantes en la vida social. (17 p.411)
}

Ahora bien, es necesario realizar algunas aclaraciones importantes respecto del modelo propuesto. 


\section{¿Cómo se conforma el contenido esencial en el caso del derecho a la salud como regla?}

Si bien no es posible abarcar toda la casuística, se pretende aquí elaborar lineamientos que permitan desarrollar a futuro un modelo más acabado del derecho a la salud como regla y principio. En este sentido, se ha dicho que "la fijación de parámetros o indicadores adecuados [...] contribuirá, pues, a la definición de fronteras de violación a los derechos económicos, sociales y culturales" (54). Por esto se fijarán algunas pautas a fin de conformar el contenido esencial del derecho a la salud y, en este sentido, sostienen Víctor Abramovich y Cristian Courtis que

\footnotetext{
...aun en ausencia de reglamentación, existen algunos parámetros para establecer al menos los contenidos básicos de estos derechos. As la noción de contenido mínimo o esencial -cuyo desarrollo tienen a cargo tanto la doctrina como la jurisprudencia- es un buen ejemplo de ello [...] esto significa que cuando los poderes públicos hayan incumplido con la obligación de dar contenido a algunos derechos sociales, los jueces pueden juzgar acerca de ese incumplimiento a partir de estos -o de algunos otros- criterios. (55 p.31)
}

Por lo tanto, se deberá considerar como contenido mínimo:

1) Todos aquellos tratamientos y/o medicamentos que se requieran para asegurar la vida de la persona. Es decir, aquellos que se requieren cuando lo que está en juego es la existencia misma (44 p.1-34). En este sentido, el Comité de Derechos Económicos, Sociales y Culturales ha sostenido que "En la Observación General No 3, [...] confirma que los Estados Partes tienen la obligación fundamental de asegurar como mínimo [...] la atención primaria básica de la salud" (56). Solo a modo de ejemplo esto implica el acceso a la alimentación mínima y al agua potable, cubrir o entregar medicamentos esenciales (por ejemplo, a las personas con cáncer), establecer centros asistenciales adecuados en estructura y accesibilidad, etc.
2) Los tratamientos referidos a sujetos de especial protección. Siguiendo los parámetros dispuestos por el artículo 75 inciso 23 de la Constitución Nacional como asimismo la doctrina elaborada por la Corte Constitucional de Colombia (57), estableciéndose que caen dentro de este grupo todos los casos en los que se encuentre afectada la salud de los niños (h), las mujeres (en lo que respecta a la salud sexual y reproductiva), los ancianos, las personas con discapacidad, los enfermos terminales (por ejemplo, VIH) (i), y los integrantes de pueblos originarios. Así, la protección de la salud de estos sujetos entra, en todos los casos, dentro del contenido mínimo que debe cumplir el Estado.

3) Todos aquellos casos que el legislador ha determinado de cumplimiento obligatorio. En el caso argentino, los contenidos mínimos que se deben cumplir en el sistema de salud están desarrollados en el Programa Médico Obligatorio (PMO) (j). En este sentido, sostiene Alexy, que "los derechos fundamentales [...] pueden ser restringidos solo a través de, o sobre la base de, normas con rango constitucional. Por ello las restricciones de derechos fundamentales son siempre o bien normas de rango constitucional o normas de rango inferior al de la Constitución, a las que autorizan a dictar normas constitucionales" (12 p.277). De esta manera, es legítimo que el contenido del derecho fundamental sea determinado por el legislador o, en su caso, el juez.

4) Todo aquello que surja de la reiteración de reglas resultado de la ponderación. El modelo de ponderación orientado por reglas propuesto por Clérico (15) es de interés en este punto, ya que las reglas posibilitan la universalización del resultado de la ponderación y no toda nueva colisión de principios requiere una ponderación, en tanto se pueda subsumir el caso nuevo bajo el antecedente de un resultadoregla de la ponderación; entonces y en principio, no se pondera en concreto (15). En este sentido, resulta importante trabajar el concepto de red de reglas resultado de ponderaciones con el principio de progresividad que ha sido desarrollado antes. Se considera que las reglas resultado de ponderaciones anteriores juegan un rol relevante a la hora de determinar el 
contenido esencial de un derecho social, pues en virtud del principio de no regresividad, una vez reconocido cierto alcance de un derecho, no se puede volver atrás. En este sentido, ese "mayor" reconocimiento puede ser tanto general (cuando por ejemplo se reconoce un determinado tratamiento vía legislativa) como individual (cuando se lo hace, por ejemplo, por vía de una sentencia). Cuando por medio de sentencias reiteradas se reconoce, mediante la ponderación, el acceso a un determinado tratamiento, esto habla de qué es lo que la sociedad entiende y reclama como contenido mínimo. Incluso no se descarta que, frente a sentencias reiteradas, sea la propia administración, o la legislatura, la que garantice, por medio de una resolución o una ley, el tratamiento para todos los casos. Recientemente, esto ocurrió con el by-pass gástrico que fue incluido en el Programa Médico Obligatorio (Ley No 26.396 del año 2008) y con los tratamientos de fertilización asistida en el ámbito de la Provincia de Buenos Aires (Ley Provincial No 14.208 del año 2011). De esta manera, a raíz de la reiteración de sentencia, y tratándose de casos donde lo que está en juego es la salud, las empresas de medicina privada, obras sociales y el sistema público de salud, deberían reconocer ese derecho. Así, mediante las reglas resultado de la ponderación, ante un nuevo caso similar, la persona no debería tener que recurrir a la justicia a fin de reclamar su derecho (esto es, que el juez aplicando el principio de proporcionalidad pondere el derecho) sino que el agente de salud debería no ceñirse a la letra de la ley (en nuestro caso, el Programa Médico Obligatorio) y brindar a la persona una solución acorde al problema que padece. Por ejemplo, si la obra social ha sido condenada en reiteradas oportunidades, mediante sentencias judiciales, a cubrir el tratamiento de bypass gástrico en los casos de obesidad mórbida, no resulta ajustado a derecho que, ante un nuevo reclamo de una persona que padece obesidad mórbida (conforme el diagnóstico del médico tratante), se la obligue a realizar un reclamo ante la justicia. Así, se afirma que las reglas que se han ido formando a través de la jurisprudencia forman parte del contenido esencial.
5) La opinión de los especialistas. Esta juega un rol muy importante por el poder decisivo que presta el experto a la hora de determinar que cierto tratamiento (por ejemplo, by-pass gástrico) es necesario para la persona y no una mera cuestión estética. En este sentido, sostiene Alegre que "la omisión de quien ejerce el poder del que están investidos los profesionales de la salud es equiparable moralmente a una acción, en este caso una acción de obstrucción al ejercicio del derecho a la salud" (59). Aquí el agente de salud (léase director del hospital, obras sociales, prepagas) debe tomar en cuenta y actuar conforme lo indicado por el médico especialista. En su caso, también se podría convocar a otros especialistas a fin de que determinen la necesariedad o no del tratamiento. El criterio entonces sería que, en caso de urgencia o necesidad del paciente, los servicios no incluidos en el Programa Médico Obligatorio deben brindarse, y luego podrá repetir la obra social o prepaga ante el Estado, garante último del derecho a la salud. Al momento de resolver cuestiones relativas al derecho a la salud no deben privilegiarse cuestiones económicas (ganancias) por sobre dicho derecho, o incluso la vida de la persona. La urgencia podrá ser determinada, por ejemplo, por un grupo de médicos independientes de la entidad a quien se reclama. El Estado verá en cada caso si los costos son reintegrados o no, teniendo en cuenta que las obras sociales y empresas privadas prestadoras de salud no deben actuar solo como entidades comerciales (deberá evaluar principalmente los réditos que el beneficiario -cliente- le ha generado a lo largo de sus aportes). En ningún caso en donde esté en juego lo que se ha caracterizado como contenido esencial pueden trasladarse los costos a los pacientes.

A raíz de lo establecido en estos puntos, y teniendo en cuenta el principio de progresividad que rige en el ámbito de los derechos sociales, se salva la objeción del peligro de petrificación del contenido mínimo (15). Este contenido esencial representa solo un piso porque los Estados están obligados a lograr avances en ese reconocimiento. Asimismo, el contenido esencial no es un bloque duro o cerrado sino que, por el 
contrario, queda abierto a fin de ir sumando mayores reconocimientos que se incorporarán al contenido esencial (ampliando el espectro de actuación del derecho a la salud como regla).

Finalmente, en caso de desconocimiento de ese mínimo, deberían establecerse sanciones que conminen a los agentes de salud (prepagas, obras sociales, directores de hospitales, ministros de salud) a cumplir la prestación (15). Estas sanciones podrían ser fiscales, impositivas, relevamiento del cargo, o toda aquella otra que logre hacer efectivo el acceso al derecho por parte de la ciudadanía.

\section{¿Cómo se efectúa la ponderación?}

En un trabajo anterior, se realizó un análisis detallado de la aplicación del examen de proporcionalidad a un caso de derecho a la salud (acceso a los tratamientos de fertilización asistida) (50), por lo que, en este punto, solo corresponde sostener que al momento de realizar el análisis de proporcionalidad y una vez que se ha afirmado que la medida es idónea y necesaria deberá realizarse el test de la "proporcionalidad en sentido estricto". Aquí deberán tenerse en cuenta los pesos abstractos y concretos de cada uno de los principios en pugna. Pueden alegarse los más diversos argumentos para determinar el peso de los principios; sin embargo, debe tenerse en cuenta el peso importante que tiene el derecho a la salud por su vinculación con otros derechos (integridad, dignidad). En los casos en los que se compromete el derecho a la salud considerado como principio, su peso será muy fuerte y deberán darse argumentos de mucho peso en su contra. Este mayor peso preestablecido al derecho a la salud se debe a la obligación que tienen los Estados de actuar progresivamente.

Tampoco se pueden alegar argumentos utilitaristas como argumentos definitorios. No corresponde realizar la pregunta respecto de cuántas personas se beneficiarían o cuántas se perjudicarían o, por ejemplo, a cuántas otras personas se podrían ayudar si no se pagara determinado tratamiento. Sin embargo, en los razonamientos se tiende a llevar a cabo esta operación de cálculo costos-beneficios. El punto es que el utilitarismo resulta violatorio de los derechos de grupos porque, al actuar teniendo en cuenta el bienestar general, borra u oculta a los grupos minoritarios (60). En ese sentido, se ha sostenido que

...los criterios utilitaristas violan los derechos de las personas. No solo se niega a algunas personas el acceso a unos tratamientos necesarios desde un punto de vista exclusivamente médi$\mathrm{co}$, sino porque se saltan [...] el derecho a la igualdad de oportunidades: discrimina a las personas por motivos de los que ellas no son responsables. (61)

Así se afirma que los argumentos utilitaristas no podrán alegarse cuando se trate de casos donde lo que está en juego es el contenido mínimo del derecho a la salud (k), y si bien se podría tomar en cuenta como un argumento más en la ponderación no otorga un peso alto, definitorio (62).

Se concluye entonces que el derecho a la salud quedaría compuesto por un contenido inderogable y por un contenido "periférico", que si bien puede ponderarse respecto de otros derechos, la justificación que debe alegarse para excluir o no desarrollar ese contenido del derecho a la salud debe responder a causas de estricta justificación.

\section{Los recursos: implicancias en el derecho a la salud como regla y como principio}

Se sostuvo que existe un contenido que el Estado no puede dejar de cumplir y otro que estará sujeto a la ponderación. Ahora bien, el principal argumento que se alega a fin de justificar el no cumplimiento de los derechos sociales es el de la escasez de recursos (tanto en lo que refiere al contenido esencial como al periférico) (I). Se ha dicho que el Estado no puede atender todas las demandas, lo cual conlleva a que algunos derechos no sean satisfechos (63 p.105). En este sentido resolvió la Corte Constitucional de Sudáfrica el caso Thiagraj Soobramoney vs. Minister of Health (Kwazulu-Natal) (64). El actor, un hombre de 41 años y desempleado, era diabético y sufría de cardiopatía isquémica y de una enfermedad cerebrovascular que lo llevó a tener un accidente cerebrovascular. Lamentablemente su estado era irreversible y al momento de 
demandar se encontraba en las etapas finales de la insuficiencia renal crónica. Su vida podría ser prolongada por medio de la diálisis renal normal. Él buscó tratamiento en la unidad renal del hospital estatal Addington en Durban. Sin embargo, el hospital podía ofrecer tratamiento de diálisis a un número limitado de pacientes (solo contaba con 20 máquinas de diálisis). De esta manera, solo los pacientes que eran candidatos para el trasplante podían acceder a las diálisis. El recurrente no era un candidato para trasplante $y$, en consecuencia no cumplía los requisitos. La Corte sostuvo que no podía expedirse sobre lo apropiado de dicho criterio, pero afirmó que si todas las personas del sur de África que sufren de insuficiencia renal crónica fueran a contar con un tratamiento de diálisis y muchos de ellos, como el recurrente, requieren un tratamiento tres veces por semana, el costo de hacerlo implicaría aumentos sustanciales en el presupuesto de salud. Y si este principio se aplicara a todos los pacientes que reclaman el acceso a un tratamiento médico costoso o medicamentos de alto costo, el presupuesto de salud tendría que ser considerablemente mayor en perjuicio de otras necesidades que tiene que cumplir el Estado. Por lo tanto, no se puede dejar de reconocer que los recursos ocasionan graves problemas a la hora de desarrollar los derechos económicos, sociales y culturales (DESC).

Ahora bien, la escasez de recursos puede ser un argumento pernicioso con el cual pretenden justificarse las más variadas situaciones. Se considera que los recursos que maneja el Estado, a fin de cumplir con los derechos sociales, son limitados pero no escasos; por lo menos en lo que refiere al contenido mínimo que el Estado está obligado a cumplir. En cuanto a la distinción entre recursos limitados y escasos, se prefiere utilizar el primer término pues hace referencia a que los recursos tienen un límite, un extremo, son finitos. En cambio, el término escasez pareciera hacer referencia a que hay menos que lo que se requiere. Asimismo, se podría alegar que la escasez de recursos también debería afectar a los derechos civiles, pues la protección de la propiedad privada, la libertad de expresión, etc., implican recursos como los derechos sociales. Lo que pone en claro el argumento de que la escasez es la falta de políticas públicas que atiendan las cuestiones sociales prioritarias.
Este no es el momento para desarrollar una tesis acerca de cómo el Estado debería invertir esos recursos limitados, pero sí es importante poner en claro que en muchos casos ese argumento se alega incluso para dejar fuera lo que se ha caracterizado como el contenido mínimo del derecho. En el apartado 9 de las Directrices de Maastricht sobre Violaciones a los Derechos Económicos, Sociales y Culturales, se establece que las obligaciones esenciales mínimas "son aplicables independientemente de la disponibilidad de recursos" (65). Si bien los recursos existentes son limitados, esta afirmación no puede justificar las omisiones del Estado, o más, específicamente la falta de un plan estructural a fin de afrontar los problemas que traen aparejados los DESC. Por esto, "es importante distinguir entre la falta de capacidad y la falta de voluntad del Estado de cumplir sus obligaciones" (65).

Es posible dar un ejemplo de lo que es práctica recurrente en la materia. Un informe de la Asociación Civil por la Igualdad y la Justicia (ACIJ) (66) muestra las malas condiciones en que se encuentra el sistema educativo en el sur de la Ciudad de Buenos Aires (zona habitada por gente de bajos recursos), al contrario de lo que sucede en el norte de esa misma ciudad. Con lo cual, la cuestión es: si los recursos son escasos, ¿por qué entre las escuelas de una misma ciudad existen tantas diferencias? ¿No deberían estar las escuelas de las dos zonas en las mismas condiciones? Así se intenta demostrar lo peligroso de este argumento. Muchas veces no es que los recursos son escasos sino que falta, de parte de los gobiernos, un proyecto ordenado que ponga en funcionamiento adecuado esos recursos limitados (67), pues de lo contrario quienes siempre se ven afectados con esta omisión son aquellos que padecen de una desigualdad estructural y que, como se ha dicho anteriormente, carecen de acceso efectivo a la justicia para reclamar sus derechos.

Se considera que efectivamente los recursos deben racionarse, pero no en lo que afecta el contenido esencial del derecho. En este punto, se requiere un plan estructural que afronte en forma eficaz los problemas que se derivan de un derecho a la atención sanitaria en igualdad estructural de oportunidades. 


\section{Importancia del modelo propuesto}

La importancia de esta propuesta que distingue entre reglas y principios radica, sobre todo, en la situación de los titulares del derecho, especialmente de aquellas personas o grupos que carecen de acceso a la justicia. La falta de acceso a la justicia se traduce en una práctica discriminatoria institucionalizada $(68,69)$, pues los sectores con mayores recursos son los que pueden acceder a la justicia para canalizar sus reclamos y lograr el reconocimiento de su derecho, pero no así los sectores más pobres y marginales, los cuales no gozan, en la mayoría de los casos, ni siquiera del contenido mínimo que se ha caracterizado anteriormente. Por este camino, quizá la distinción del derecho a la salud como regla o como principio no sería importante si en la práctica no existiera una sistemática negación del derecho a la salud a grupos desaventajados.

De esta manera, si se considera al derecho a la salud como principio, la persona deberá recurrir a la administración o a la justicia a fin de que determine el alcance de su derecho, lo que no debería suceder respecto del contenido esencial, pues lo que está en juego es la propia vida de la persona. Lo que se propone es que el contenido mínimo del derecho debe ser respetado a nivel administrativo (agentes de salud) sin necesidad de tener que realizar planteos judiciales a fin de ver efectivizado dicho derecho. Debe tenerse en cuenta que, si bien es cierto que el campo de la salud está influido por una gran cantidad de variables (políticas, económicas, científicas, etc.), el accionar de los agentes de salud debe estar guiado siempre por el cumplimiento del derecho a la salud y nunca por otras cuestiones, que podemos considerar "secundarias" desde una visión igualitaria de los derechos. Así, ante un reclamo de acceso a determinado tratamiento, la lógica que debe predominar en los prestadores no es la de la negativa sino, por el contrario, la de dar cumplimiento a ese derecho y en todo caso discutir cuál es la forma de acceso más adecuada. Sin duda, la determinación del contenido esencial del derecho marca un camino más claro, pues los prestadores podrían conocer de antemano cuál es el accionar debido.

En este sentido, constatado por un médico o autoridad administrativa el hecho des- cripto como contenido mínimo, es obligación del Estado actuar en forma urgente sin necesidad de comprobar algún otro tipo de circunstancia. En referencia, por ejemplo, al caso de los niños desnutridos en el Chaco (m): comprobada dicha situación, el gobierno (provincial o nacional o ambos) debe actuar sin tomar en consideración quién debe cumplir esa obligación (problema de competencias). Lo mismo en los casos de obras sociales o prepagas, comprobada determinada enfermedad, debe responder sin que sea posible alegar la ausencia del tratamiento en el Programa Médico Obligatorio o asuntos administrativos. Estas cuestiones secundarias, desde el punto de vista del derecho a la salud y la vida, podrán ser discutidas posteriormente.

La división del derecho a la salud como regla y principio se debe a que el riesgo inminente para la vida (existencia) no es lo mismo que afectación del derecho a la salud. Esta tesis se opone a la planteada por un importante sector de la doctrina que sostiene que es posible limitar los derechos sociales, aunque solo serían admisibles aquellas restricciones que superaran un escrutinio estricto de razonabilidad (70 p.124). La Corte Interamericana de Derechos Humanos ha dicho que:

El derecho a la vida es un derecho humano fundamental, cuyo goce es un prerrequisito para el disfrute de todos los demás derechos humanos. De no ser respetado, todos los derechos carecen de sentido. En razón del carácter fundamental del derecho a la vida, no son admisibles enfoques restrictivos del mismo. En esencia, el derecho fundamental a la vida comprende, no solo el derecho de todo ser humano de no ser privado de la vida arbitrariamente, sino también el derecho a que no se le impida el acceso a las condiciones que le garanticen una existencia digna. Los Estados tienen la obligación de garantizar la creación de las condiciones que se requieran para que no se produzcan violaciones de ese derecho básico y, en particular, el deber de impedir que sus agentes atenten contra él. (71 p.40)

Así, en los casos que caen dentro del primer modelo (regla) el agente de salud o legislador no puede ponderar sino que debe en forma 
urgente y obligatoria hacer efectivo el derecho haciendo lugar a lo solicitado. Ahora bien, en los casos que caen dentro del segundo modelo (principios), que no son por ello menos importantes y penosos vistos desde la persona que lo sufre, se requiere la ponderación de principios.

Asimismo, la determinación de este contenido esencial sirve para definir indicadores de progresividad (49 p.55). El artículo 19 del Protocolo de San Salvador (72) establece que los Estados Parte deberán presentar informes periódicos respecto de las medidas progresivas que hayan adoptado para asegurar el debido respeto de los derechos en él establecidos. En este sentido, resulta relevante contar con un núcleo desde el cual medir los avances o retrocesos del país en materia de derechos sociales, especialmente de derecho a la salud. Sin este mínimo, no será posible evaluar la implementación de medidas que hacen a la progresividad de dicho derecho.

\section{CONCLUSIÓN}

Si bien resulta necesario continuar con la línea de reconocimiento de derechos sociales, específicamente del derecho a la salud, es urgente tener presente que dicho sistema es insuficiente porque existen grupos que no pueden acceder a la justicia. Así, el Estado nacional, como fiador final del derecho a la salud, debe adoptar medidas efectivas y congruentes que tomen en cuenta las situaciones de poder asimétricas que existen en la sociedad para hacer efectivo el derecho a la salud. En este sentido, la lectura en clave social del principio de igualdad demanda un Estado no neutral, capaz de reconocer diferencias sociales y culturales y disponer acciones afirmativas o de desequilibrio destinadas a superar situaciones de desventaja o retraso de ciertos colectivos o sectores sociales postergados (argumento del artículo 75 inciso 23 de la Constitución Nacional) (34 p.268).

En esta dirección, la disyuntiva no consiste en ampliar el acceso a la justicia o mejorar el sistema de salud. La ampliación del acceso a la justicia es necesaria a fin de que los grupos desaventajados puedan presentar sus reclamos, pero es insuficiente cuando se trata del reclamo de derechos donde lo que está en juego es la vida de la persona o incluso de un colectivo. Entonces, no debe conformar el reconocimiento de los derechos sociales solo a nivel judicial, porque si bien el Poder Judicial puede ser un actor importante a la hora de dar respuestas a grupos tradicionalmente excluidos, en pocos casos esas respuestas son universales o estructurales sino que generalmente solo benefician al o a los reclamantes. Además, se deben tener en cuenta los costos que representa para el Estado el servicio de justicia (costos que podrían ser disminuidos si las personas no tuvieran que reclamar el cumplimiento de sus derechos por esta vía). En este sentido, se destaca que "solo con políticas de corte universal se garantizan mínimos comunes irrenunciables que, a la vez, promueven mejores garantías de igualdad y no discriminación" (37 p.307).

Por esto, se propone caracterizar el derecho a la salud como regla y como principio, y si bien no se deja de reconocer el carácter debatible que presenta este modelo, especialmente en lo que respecta al contenido esencial del derecho, se considera que esta evaluación es mejor a la propuesta de que todos los derechos y todos los contenidos sean ponderables, pues esto conlleva a la desigualdad respecto de aquellos que no puedan reclamar. Se ha tomado conciencia de que no se puede determinar el contenido esencial con certeza y seguridad jurídica (teniendo en cuenta, por ejemplo, que el derecho a la salud se encuentra en permanente tensión con el desarrollo tecnológico y de las industrias de salud) y que, por lo tanto, quizá este modelo no elimina totalmente la cuestión de la litigiosidad en materia de salud, pero se considera que el modelo propuesto constituye una herramienta eficaz a fin de orientar el accionar de los agentes prestadores en el reconocimiento de un acceso más igualitario al derecho a la salud.

Debe tenerse en cuenta que esta idea de derecho a la salud como regla y como principio no solo está destinada a ser aplicada por los tribunales de justicia, sino principalmente para ser tenida en cuenta por los legisladores y por los agentes de salud a la hora de resolver el acceso al derecho a la salud. Parafraseando a Dworkin (73), se concluye que si nos tomamos los derechos en serio ha de afirmarse que los derechos sociales tienen un contenido inquebrantable, que debe ser respetado tanto por los distintos órganos 
del Estado (poder legislativo, ejecutivo y judicial) como por los particulares. Esto significa no solo que ese mínimo no deba ser violentado sino, sobre todo, que debe ser desarrollado en condiciones de igualdad estructural.

\section{AGRADECIMIENTOS}

Este artículo se realizó en el marco de una estancia de investigación sobre derecho a la salud, financiada por una beca del Programa ALEARG (DAAD/ME), de la Deutscher Akademischer Austausch Dienst y el Ministerio de Educación de la Nación, desarrollada en el Instituto Max Planck de Derecho Público Comparado y Derecho Internacional (Heidelberg, Alemania). Agradezco a Leticia Vita sus valiosos aportes en la realización de este trabajo.

\section{NOTAS FINALES}

a. En lo que respecta a Argentina, se pueden consultar los trabajos de la Asociación de Derechos Civiles (28); del Centro de Estudios Legales y Sociales $(29,30)$ y, en general, la Base de Datos de Jurisprudencia de la Red Internacional para los Derechos Económicos, Sociales y Culturales (Red-DESC).

b. Son pioneros en este sentido los fallos de la Corte Suprema de Justicia de la Nación: "Campodónico de Beviacqua, Ana Carina c/ Ministerio de Salud y Acción Social - Secretaría de Programas de Salud y Banco de Drogas Neoplásicas" del 24/10/2000; "Monteserín, Marcelino O. c/ Estado Nacional" del 16/10/01; "Etcheverry, Roberto E. c/ Omint Sociedad Anónima de Servicios" del 3/3/2001; "Hospital Británico de Buenos Aires cl Estado Nacional (Ministerio de Salud y Acción Social)" del $31 / 03 / 01$. La doctrina sentada por estos fallos ha sido reiterada en numerosas decisiones tanto por la Corte como por los tribunales inferiores, que incluso han ampliado el espectro de protección. Sobre líneas jurisprudenciales en esta materia ver Clérico (31), Clérico y Scioscioli (32), entre otros.

c. Sobre la distribución de obligaciones del Estado nacional y provinciales que surgen del derecho a la salud, a la luz de la reforma constitucional de 1994, ver Clérico (33).

d. Conforme la clasificación de Herbert Lionel Adolphus Hart, se trataría de "casos fáciles" pues a primera vista puede determinarse si está o no comprendido por la norma que pretende aplicarse (17 p.140). Aplican explícitamente el concepto de casos fáciles en materia de derecho a la salud: Clérico (39 p.30), Clérico y Scioscioli (43). e. En este sentido, el Art. 19 Inc. 2 de la Ley Federal alemana establece que en ningún caso un derecho fundamental podrá ser afectado en su contenido esencial (19.2 In keinem Falle darf ein Grundrecht in seinem Wesensgehalt angetastet werden). En nuestro país, el concepto de contenido esencial de los derechos puede surgir de los Artículos 14, 28 y 99 Inc. 2 de la Constitución Nacional referidos a la reglamentación de los derechos y el espíritu de las leyes. Un derecho resulta alterado, modificado, cuando se compromete su núcleo. Corresponde aclarar que se prefiere el término "contenido esencial" al término "contenido mínimo" pues, a primera vista, este refiere a algo pequeño, en cambio esencial refiere a lo más importante (sustancial) que puede no ser mínimo.

f. Rodolfo Arango, con referencia a los derechos sociales en general y citando jurisprudencia del Tribunal Constitucional Alemán, se refiere al derecho mínimo vital. Sostiene que consiste en "la satisfacción de las necesidades materiales básicas de todos los seres humanos..." (45 p.212). Asimismo, se ha dicho que "This minimum core might not be easy to define, but includes at least the minimum decencies of life consistent with human dignity. No one should be condemned to a life below the basic level of dignified human existence. The very notion of individual rights presupposes that anyone in that position should be able to obtain relief from a court" (48 p.22-23).

g. "El principio de proporcionalidad se aplica, cuando se debe concretar y fundamentar una norma adscripta de derecho fundamental" (12). Puede consultarse además a Clérico (15) y Bernal Pulido (17 p. 138). Para los casos de omisión o acción insuficiente se denomina prohibición de protección deficiente (Untermassverbot). Sobre 
la prohibición de protección insuficiente en materia de salud, ver su aplicación y desarrollo en Clérico $(38,53)$.

h. Este es el criterio que ha seguido la Corte Suprema de Justicia de la Nación en los casos Lifschitz (15/06/2004) y Maldonado (23/11/2004), entre otros.

i. Este es el criterio que ha seguido la Corte Suprema de Justicia de la Nación en los casos Hospital Británico y Asociación Benghalensis.

j. El Programa Médico Obligatorio (PMO) conforma "un conjunto de servicios de carácter obligatorio como piso prestacional por debajo del cual ninguna persona debería ubicarse en ningún contexto" (Resolución 939/2000 del Ministerio de Salud y la Resolución 201/02 referida a la ampliación del Plan Médico Obligatorio de Emergencia (PMOE) producto de la declaración de Emergencia Sanitaria Nacional (Decreto 486/2002 del Poder Ejecutivo Nacional) y a su actualización en virtud de la Resolución 1991/2005 del Ministerio de Salud y Ambiente entre otras). El PMO ha sido actualizado en forma constante ya sea por vía legislativa, resolutiva o incluso judicial (58). Es de destacar que si bien mediante el PMO se logró la unificación de las prestaciones que debían brindar los prestadores de salud, su implementación ha traído aparejados varios conflictos que se plantearon en sede judicial. Por ejemplo, en relación con el tiempo de carencia (enfermedades preexistentes) que fijaban las obras sociales y empresas de medicina privada (por ejemplo, fallo "Unión de Usuarios y Consumidores c/ Compañía Euromédica de Salud S.A.", CSJN, 8/4/2008); también, en cuanto a la interpretación como un piso mínimo que limitaba estrictamente las prestaciones y que no se veía afectado por las actualizaciones que se realizaran (por ejemplo, fallo "Cambiaso Péres de Nealón Celia M. A. y otros c/ Centro de Educación Médica e Investigaciones Médicas", CSJN, 28/8/2007), etc. k. Esto es lo que sucede en la medida cautelar resuelta el 2/08/2010 por el juzgado Civil y Comercial Federal $N^{\circ} 2$, en la que se ordenó al Ministerio de Salud pagar la cobertura del tratamiento oncológico a favor del paciente Aquiles Víctor Hugo Misiti quién carecía de obra social, cuyo costo era de aproximadamente 45 mil pesos por sesión. En el caso, la quimioterapia convencional no dio resultados positivos para el tratamiento de la enfermedad, por lo que le fue recomendado al paciente someterse a una "quimioembolización hepática con esferas CD Beads". El juez entendió que "el tratamiento de la enfermedad que padece el actor no admite dilaciones" (considerando $\mathrm{n}^{\circ} \mathrm{IV}$ ). Así, ordenó implementar "en forma inmediata, integral, ininterrumpida y cubriendo el 100 por ciento de su costo el tratamiento prescripto y la medicación que dan cuenta las prescripciones médicas". De esta manera, el juez no tuvo en cuenta argumentos utilitaristas ni admitió argumentos relativos a la escasez de recursos (aun cuando el costo del tratamiento era muy alto), sino que ante la posible afectación de lo que hemos caracterizado como contenido esencial el juez resolvió a favor del demandante.

I. La Corte Suprema de Justicia de la Nación determinó que el hipotético desequilibrio financiero no resulta suficiente para dejar de cumplir una obligación mínima. Ver los casos Hospital Británico de Buenos Aires c/ Estado Nacional (31/03/01) y "Unión de Usuarios y Consumidores c/ Compañía Euromédica de Salud S.A." (08/04/2008).

m. Chaco es una provincia argentina que ha sido denunciada, conjuntamente con el Estado nacional, por el Defensor del Pueblo de la Nación ante la Corte Suprema de Justicia de la Nación por la grave desnutrición, falta de acceso al agua y a asistencia de salud que padecen los integrantes de la comunidad toba que allí habitan. Al respecto ver CSJN, "Defensor del Pueblo de la Nación c/ Estado Nacional y otra (Provincia del Chaco) s/ Proceso de Conocimiento", Sentencia del 18/09/2007.

\section{REFERENCIAS BIBLIOGRÁFICAS}

1. Organización Mundial de la Salud. Constitución de la Organización Mundial de la Salud: Documentos básicos, suplemento de la 45a edición. [Internet]. Ginebra: OMS; 2006 [citado 12 feb 2012]. Disponible en: http://www.who.int/governance/eb/who_constitution_sp.pdf.
2. Argentina. Constitución Nacional. Declaraciones, derechos y garantías, Art. 16 [Internet]. Buenos Aires: Senado de la Nación Argentina [citado 12 feb 2012]. Disponible en: http://www.senado. gov.ar/web/interes/constitucion/capitulo1.php.

3. Argentina. Constitución Nacional. Declaraciones, derechos y garantías, Art. 20 [Internet]. Buenos Aires: Senado de la Nación Argentina [citado 12 feb 
2012]. Disponible en: http://www.senado.gov. ar/web/interes/constitucion/capitulo1.php.

4. Argentina. Constitución Nacional. Atribuciones del Congreso, Art. 75, Inc. 22-23 [Internet]. Buenos Aires: Senado de la Nación Argentina [citado 12 feb 2012]. Disponible en: http://www.senado. gov.ar/web/interes/constitucion/atribuciones.php.

5. Naciones Unidas. Declaración de los Derechos Humanos. Art. 2. París: Asamblea General de las Naciones Unidas; 1948. Resolución 217 A (III).

6. Naciones Unidas. Declaración de los Derechos Humanos. Art. 7. París: Asamblea General de las Naciones Unidas; 1948. Resolución 217 A (III).

7. Organización de los Estados Americanos. Convención Americana sobre Derechos Humanos (Pacto De San José). Art. 1: Obligación de Respetar los Derechos, Inc.1. San José: OEA; 1969.

8. Organización de los Estados Americanos. Convención Americana sobre Derechos Humanos (Pacto De San José). Art. 2: Deber de Adoptar Disposiciones de Derecho Interno. San José: OEA; 1969.

9. Organización de los Estados Americanos. Convención Americana sobre Derechos Humanos (Pacto De San José). Art. 24: Igualdad ante la Ley. San José: OEA; 1969.

10. Naciones Unidas. Pacto Internacional de Derechos Civiles y Políticos. Art. 2, Inc. 1 [Internet] 1966 [citado 14 feb 2012]. Disponible en: http://www2.ohchr.org/spanish/law/ccpr.htm.

11. Naciones Unidas. Pacto Internacional de Derechos Civiles y Políticos. Art. 26 [Internet] 1966 [citado 14 feb 2012]. Disponible en: http://www2.ohchr.org/spanish/law/ccpr.htm.

12. Alexy, R. (1993). Derecho a acciones positivas del Estado (prestaciones en sentido amplio). En: Teoría de los derechos fundamentales. Madrid: CEPC, Madrid; 1993. p. 419-502.

13. Abramovich V, Courtis C. Los derechos sociales como derechos exigibles. Madrid: Trotta; 2002.

14. Ferrajoli L. Prólogo. En: Abramovich V, Courtis C. Los derechos sociales como derechos exigibles. Madrid: Trotta; 2002. p. 9-14.

15. Clérico L. Die Struktur der Verhältnismässigkeit. Baden-Baden: Nomos; 2001.
16. Clérico L. Hacia un modelo de la ponderación orientado por reglas para la solución de conflictos entre derechos fundamentales. En: Teoría y práctica del derecho constitucional. Quito: Ministerio de Justicia y Derechos Humanos; 2010.

17. Bernal Pulido C. El principio de proporcionalidad y los derechos fundamentales. 3a ed. Madrid: Centro de Estudios Políticos y Constitucionales; 2007.

18. Atria F. ¿Existen derechos sociales? Discusiones [Internet]. 2004 [citado 12 feb 2012];(4). Disponible en: http://bib.cervantesvirtual.com/FichaObra.html?Ref $=15570$.

19. Gargarella R. Derecho y disociación. Un comentario a ¿Existen derechos sociales? Discusiones [Internet]. 2004 [citado 12 feb 2012];(4). Disponible en: http://bib.cervantesvirtual.com/FichaObra.html?Ref $=15571$.

20. Bernal Pulido C. Fundamento, concepto y estructura de los derechos sociales. Una crítica a ¿Existen derechos sociales? Discusiones [Internet]. 2004 [citado 12 feb 2012];(4). Disponible en: http://bib.cervantesvirtual.com /FichaObra.html?Ref = 15573 .

21. Naciones Unidas. Observaciones generales 13: El derecho a la educación. Punto 45. [Internet]. Comité de Derechos Económicos, Sociales y Culturales, $21^{\circ}$ período de sesiones; 1999 [citado 12 feb 2012]. Disponible en: http://www.unhchr.ch/tbs/doc.nsf/(Symbol)/E.C.1 2.1999.10.Sp?OpenDocument.

22. Corte Interamericana de Derechos Humanos. Caso Acevedo Buendía y otros vs. Perú [Internet]. Sentencia de 1 de julio de 2009 [citado 12 feb 2012]. Disponible en: http://www.corteidh.or.cr/ docs/casos/articulos/seriec_198_esp.pdf.

23. Courtis C. El mundo prometido: Escritos sobre derechos sociales y derechos humanos. México DF: Fontamara; 2009.

24. Naciones Unidas. Observación general № 14: El derecho al disfrute del más alto nivel posible de salud. Punto 31 [Internet]. Ginebra: Comité de Derechos Económicos, Sociales y Culturales, 22 período de sesiones; 2000 [citado 12 feb 2012] Disponible en: http://www.unhchr.ch/tbs/doc.nsf/ (Symbol)/E.C.12.2000.4.Sp?OpenDocument.

25. Arango R. La prohibición de retroceso en Colombia. En: Courtis C, compilador. Ni un paso atrás. La prohibición de regresividad en materia de derechos sociales. Buenos Aires: Del Puerto; 2006. 
26. Corte Suprema de Justicia de la Nación. Asociación Benghalensis y Otros (01/06/2000 Fallos: 323:1339). En: Derecho a la Salud. Buenos Aires: Corte Suprema de Justicia de la Nación; 2010. p. 133-152.

27. Naciones Unidas, Asamblea General. Distintos criterios y medios posibles dentro del sistema de las Naciones Unidas para mejorar el goce efectivo de los derechos humanos y las libertades fundamentales [Internet]. Resolución 32/130, 16 de diciembre 1977 [citado 12 feb 2012]. Disponible en: http://daccess-ddsny.un.org/doc/RESOLUTION/GEN/NR0/320/13/I MG/NR032013.pdf?OpenElement.

28. Asociación de Derechos Civiles. La Corte y los Derechos 2005/2000. Buenos Aires: Siglo XXI Editores; 2008.

29. Centro de Estudios Legales y Sociales. Derechos Humanos en la Argentina: Informe Anual 2007. Buenos Aires: Siglo XXI Editores; 2007.

30. Centro de Estudios Legales y Sociales. Derechos Humanos en la Argentina: Informe Anual 2009. Buenos Aires: Siglo XXI Editores; 2009

31. Clérico L. La jurisprudencia de la Corte sobre medicina prepaga en el contexto de un sistema de salud con fronteras "híbridas". Buenos Aires: Jurisprudencia Argentina; 2010.

32. Clérico L, Scioscioli S. El derecho a la salud de las personas con discapacidad y el impacto del derecho constitucional internacionalizado en la regulación de las actividades prepagas: el caso "CEMIC". Jurisprudencia Argentina. 2008;(II):1-43.

33. Clérico L. ¿El argumento del federalismo vs. el argumento de igualdad?: El derecho a la salud de las personas con discapacidad. Revista Jurídica [Internet] 2010 [citado 10 feb 2012];11(1):93:117. Disponible en http://www.palermo.edu/derecho /revista juridica/pub-11/11Juridica05.pdf.

34. Abramovich V, Pautassi L. El derecho a la salud en los tribunales: Algunos efectos del activismo judicial sobre el sistema de salud en Argentina. Salud Colectiva. 2008;4(3):261-282.

35. Scioscioli S. Naturaleza y alcance del acceso a la salud en la jurisprudencia de la Corte Suprema de Justicia de la Nación: Su estudio desde la perspectiva del análisis económico del derecho y su filosofía económica. [Tesis de Maestría en Derecho y Economía]. Buenos Aires: Universidad de Buenos Aires; 2007.
36. Santos BS. Sociología jurídica crítica: para un nuevo sentido común en el derecho. Madrid: Trotta; 2009.

37. Abramovich V, Pautassi L, compiladores. La revisión judicial de las políticas sociales: Estudio de casos. Buenos Aires: Del Puerto; 2009.

38. Corte Suprema de Justicia de la Nación. Ramos, Marta Roxana y Otros (12/03/2002 Fallos: 325:396). En: Derecho a la Salud. Buenos Aires: Corte Suprema de Justicia de la Nación; 2010. p. 234-244.

39. Clérico L. El derecho a la alimentación de los niños, la presunción de exclusión y la necesidad de cambiar el estándar de control de las obligaciones estatales iusfundamentales. "Rodríguez", "Comunidad Toba del Chaco" y la sombra de "Ramos". Jurisprudencia Argentina. 2007;IV(supl. 6):S1-S34.

40. Programa de las Naciones Unidas para el Desarrollo. Informe Nacional sobre Desarrollo Humano 2010: Desarrollo humano en Argentina: trayectos y nuevos desafíos [Internet]. Anexo $\mathrm{N}^{\circ}$ 3. Buenos Aires: PNUD; 2010 [citado 12 feb 2012]. Disponible en: www.undp.org.ar/desarroIlohumano/docsIDH2010/PNUD_INDH_2010_ Nov_2010.pdf.

41. Programa de las Naciones Unidas para el Desarrollo. Informe Nacional sobre Desarrollo Humano 2010: Desarrollo humano en Argentina: trayectos y nuevos desafíos [Internet]. Buenos Aires: PNUD; 2010 [citado 12 feb 2012]. Disponible en: www.undp.org.ar/desarrollohumano/docsIDH2010/PNUD_INDH_2010_Nov_ 2010.pdf.

42. Naciones Unidas. Observación General No 14: El derecho al disfrute del más alto nivel posible de salud. Punto 47 [Internet]. Ginebra: Comité de Derechos Económicos, Sociales y Culturales, $22^{\circ}$ período de sesiones; 2000 [citado 12 feb 2012]. Disponible en: http://www.unhchr.ch/tbs/doc.nsf/ (Symbol)/E.C.12.2000.4.Sp?OpenDocument.

43. Clérico L, Scioscioli S. La judicialización de los derechos de prestación: el caso del derecho a la salud y el derecho a la educación. Un estudio comparado de su exigibilidad. En: Actas X Congreso Nacional de Sociología Jurídica. Córdoba: Universidad Nacional de Córdoba; 2009.

44. Clérico L. El examen de proporcionalidad: entre el exceso por acción y la insuficiencia por omisión o defecto. En: Carbonell M, editores. El principio de proporcionalidad en el Estado constitucional. Bogotá: Universidad del Externado; 2008. 
45. Arango R. El concepto de los derechos sociales fundamentales. Bogotá: Legis; 2005.

46. Drews C. Die Wesensgehaltsgarantie des Art. 19 II GG. Baden-Baden: Nomos; 2005.

47. Gavara de Cara JC. Derechos fundamentales y desarrollo legislativo. La garantía del contenido esencial de los derechos fundamentales en la Ley Fundamental de Bonn. Madrid: Centro de Estudios Constitucionales; 1994.

48. Constitutional Court of South Africa. Case CCT 8/02 [Internet]. 2002 [citado 12 feb 2012]. Disponible en: http://www.saflii.org/za/cases/ ZACC/2002/15.pdf.

49. Parra Vera O. El contenido esencial del derecho a la salud y la prohibición de regresividad. En: Courtis C, compilador. Ni un paso atrás: La prohibición de regresividad en materia de derechos sociales. Buenos Aires: Del Puerto; 2006.

50. Ronconi L. ¿Debe el Estado satisfacer los tratamientos de reproducción asistida?: Un análisis a la luz del principio de proporcionalidad. La Ley, Suplemento de Derecho Constitucional. 2010;(Supl):17-28.

51. Ronconi L. La aplicación del examen de proporcionalidad para determinar las obligaciones estatales de prestación: ¿Debe el Estado satisfacer los tratamientos de reproducción asistida? En: Beade G, Clérico L, editores. Desafíos a la Ponderación. Bogotá: Universidad del Externado; 2011.

52. Alexy R. La construcción de los derechos fundamentales. Buenos Aires: Ad Hoc; 2010.

53. Clérico L. Proporcionalidad, prohibición de insuficiencia y la tesis de la alternatividad. Buenos Aires: La Ley; 2010.

54. CEPAL, IIDH. Informe del seminario sobre la propuesta de transformación productiva con equidad y los derechos económicos, sociales y culturales. Revista IIDH. 1994;20:279-294.

55. Abramovich V, Courtis C. El umbral de la ciudadanía: El significado de los derechos sociales en el Estado Social Constitucional. Buenos Aires: Editores del Puerto; 2006.

56. Naciones Unidas. Observación General No 14 : El derecho al disfrute del más alto nivel posible de salud. Punto 43 [Internet]. Ginebra: Comité de Derechos Económicos, Sociales y Culturales, $22^{\circ}$ período de sesiones; 2000 [citado 12 feb 2012]. Disponible en: http://www.unhchr.ch/tbs/doc.nsf/ (Symbol)/E.C.12.2000.4.Sp?OpenDocument.
57. Ronconi L. El derecho a la salud en perspectiva comparada. El caso de Argentina $y$ Colombia. En: Clérico L, Aldao M, Ronconi L. Salud: sobre (des)igualdades y derechos. Buenos Aires: Abeledo Perrot; 2012.

58. Clérico L, Ronconi L, Aldao M, Sciocioli, S. Notas y preguntas sobre el Marco regulatorio de la medicina prepaga. En: Jurisprudencia Argentina. Buenos Aires: AbeledoPerrot; 2011. p. 3-35.

59. Alegre M. Opresión a conciencia: La objeción de conciencia en la esfera de la salud sexual y reproductiva. En: Derecho y sexualidades: Seminario en Latinoamérica de Teoría Constitucional y Política. Buenos Aires: Librarias; 2009.

60. Garagarella R. Las Teorías de la Justicia después de Rawls: Un breve manual de filosofía política. Barcelona: Paídos; 2004.

61. Puyol-González A. Ética, derechos y racionamiento sanitario. Doxa. 1999;(22):581-605.

62. Beade G. El carácter deontológico de la ponderación: Un análisis de las posiciones de Alexy y Dworkin con relación al caso de la Ley de Seguridad Aérea alemana. En: Beade G, Clérico L, editores. Desafíos a la Ponderación. Bogotá: Universidad del Externado; 2011.

63. Grosman L. Escasez e Igualdad. Buenos Aires: Libraria; 2008.

64. Constitutional Court of South Africa. Soobramoney $v$ Minister of Health (KwazuluNatal). Case CCT 32/97 [Internet]. 1997 [citado 12 feb 2012]. Disponible en: http://www.saflii.org/za/ cases/ZACC/1997/17.html.

65. Naciones Unidas. Directrices de Maastricht sobre Violaciones a los Derechos Económicos, Sociales y Culturales. Ginebra: Comité de Derechos Económicos, Sociales y Culturales; 2000.

66. Asociación Civil por la Igualdad y la Justicia. La discriminación educativa en la Ciudad de Buenos Aires [Internet] 2009 [citado 12 feb 2012]. Disponible en: http://acij.org.ar/wp-content/uploads/2011/11/La-discriminaci \%C3\%B3neducativa-en-la-Ciudad-de-Buenos-Aires.pdf.

67. Videla E. Desigualdad a la hora de gastar. Página/12 [Internet]. 1 nov 2010 [citado 12 feb 2012]. Disponible en: http://www.pagina12. com.ar/diario/sociedad/3-156068-2010-1101.html. 
68. Naciones Unidas. Observación General No 4: La salud y el desarrollo de los adolescentes en el contexto de la Convención sobre los Derechos del Niño. Párrafo 19. Ginebra: Comité de los Derechos del Niño; 2003.

69. Naciones Unidas. Observación General No 20: La no discriminación y los derechos económicos, sociales y culturales. Ginebra: Comité de Derechos Económicos, Sociales y Culturales; 2009.

70. Pisarello G. Del estado social tradicional al estado social constitucional: por una protección compleja de los derechos sociales. En: Carbonell M, compilador. Teoría constitucional y derechos fundamentales. México: Comisión Nacional de derechos Humanos; 2002.
71. Corte Interamericana de Derechos Humanos. Caso de los "Niños de la Calle" (Villagrán Morales y otros) vs. Guatemala [Internet]. 19 nov 1999 [citado 15 feb 2012]. Disponible en: http://www.corteidh.or.cr/docs/casos/articulos/se riec_63_esp.pdf.

72. Organización de los Estados Americanos. Protocolo Adicional a la Convención Americana sobre Derechos Humanos en Materia de Derechos Económicos, Sociales y Culturales "Protocolo de San Salvador". San Salvador: Convención Americana sobre Derechos Humanos; 1988.

73. Dworkin R. Taking rights seriosuly. London: Gerald Duckworth; 1977.

\section{FORMA DE CITAR}

Ronconi LM. Derecho a la salud: un modelo para la determinación de los contenidos mínimos y periféricos. Salud Colectiva. 2012;8(2):131-149.

Recibido el 13 de diciembre de 2011

Versión final presentada el 19 de abril de 2012

Aprobado el 25 de abril de 2012 